\title{
Clinical implications of alignment of upper and lower cervical spine
}

\author{
S. K. Sherekar, Y. R. Yadav, A. S. Basoor, Arvind Baghel, Nelson Adam \\ Neurosurgery Unit, NSCB Medical College, Jabalpur, Madhya Pradesh, India
}

\begin{abstract}
Aims and Objectives: The alignment of upper and lower cervical spine is presumed to be closely interrelated and the knowledge of this is mandatory when performing occipito-cervical and upper cervical fusions. The aim of this study was to establish standard values for upper and lower cervical spine alignment in the Indian population. Materials and Methods: Five hundred eighteen asymptomatic volunteers (261 males and 257 females) between 12 and 80 years of age underwent lateral radiography with their neck in the neutral position. Angles for occipital to $2^{\text {nd }}$ cervical $(\mathrm{Oc}-\mathrm{C} 2), 1^{\text {st }}$ to $2^{\text {nd }}$ cervical (C1C2) and sagittal alignment of $2^{\text {nd }}$ to $7^{\text {th }}$ cervical vertebrae (C2-C7) were measured. Statistical analyses were performed using a statistical package SPSS 10 for windows and the students ' $\mathrm{t}$ ' test. Results: The mean Oc-C2, C1-C2 and $\mathrm{C} 2-\mathrm{C} 7$ angles were $14.66+9.5^{\circ}, 25.6+7.9^{\circ}$ and 16.8 $+12.7^{\circ}$ in male, while same angles in female were 15.59 $+8.26^{\circ}, 26.9+6.8^{\circ}$ and $9.11+10.4^{\circ}$ respectively. Weak statistically significant negative correlation was observed between the measured angles of the upper (Oc-C2 and $\mathrm{C} 1-\mathrm{C} 2)$ and lower (C2-C7) cervical spines, which means if the lordosis of the occiput and upper cervical spine increases (if the Oc-C2 angle increases), the alignment of lower cervical spine becomes kyphotic and vice versa. This negative correlation was stronger between the Oc-C2 and $\mathrm{C} 2-\mathrm{C} 7$ angles than between the $\mathrm{C} 1-\mathrm{C} 2$ and $\mathrm{C} 2-\mathrm{C} 7$ angles. Conclusions: Relationship between alignment of the upper and the lower cervical spine should be taken into consideration when performing cervical fusion.
\end{abstract}

Key words: Cervical spine, cervical spine fusion, occiput, spinal alignment

\section{Introduction}

The alignment of upper and lower cervical spine is presumed to be closely interrelated and the knowledge of this is mandatory when performing occipito-cervical and upper cervical fusions. Several investigators have studied the development of postoperative malalignment of lower cervical spine after fusion of upper cervical spine and occiptio-cervical junction; ${ }^{[1-6]}$ however, there is no such study in the Indian population. Degenerative changes occurred in those cases in which normal alignment of upper and lower cervical spine was not taken into consideration. Atlantoaxial fusions are quite commonly done in congenital atlantoaxial dislocation (AAD) and occipitoaxial fusion is also done in the above condition when $\mathrm{C} 1$ arch is absent. Other level cervical fusions are also commonly done following traumatic, degenerative conditions and inflammatory dislocations of upper and lower cervical spine. The purpose of this study was to establish standard values for normal alignment of upper and lower cervical spine in healthy individuals of the Indian population. The goal is to be able to use these data as control values when performing cervical fusions.

\section{Materials and Methods}

This study was carried out in the neurosurgery unit of our institution from Nov. 2003 to Oct. 2004. This study involved asymptomatic volunteers between 12 and 80 years of age attending neurosurgery OPD, casualty and hospitalized individuals. Informed consent was taken and these individuals were not having cervical spine problems. They did not have any history of cervical disease or trauma and exhibited no neck, shoulder or arm symptoms. All individuals underwent lateral radiography with their neck in the neutral position. (Neutral position: sitting on stool, they were instructed to look straight ahead in a relaxed position and film-tube distance was set at $1.5 \mathrm{~m}$.)

The normal lateral neutral cervical spine was defined using 5 curves (lines). ${ }^{[7,8]}$ The following angles were measured using radiographs: (a) Occipital to $2^{\text {nd }}$ cervical (Oc-C2): Angle between McGregor line ${ }^{[9]}$ and the line tangential to the inferior aspect of the axis was defined as the Oc-C2 angle (b) $1^{\text {st }}$ and $2^{\text {nd }}$ cervical (C1-C2): angle between inferior aspect of atlas and axis (c) sagittal alignment of $2^{\text {nd }}$ to $7^{\text {th }}$ cervical vertebrae (C2-C7): angle between 
the posterior aspect of vertebral bodies of $\mathrm{C} 2$ and $\mathrm{C} 7$ as shown in [Figure 1]. All statistical analysis was performed using a statistical package (SPSS version 10.0 for windows). The chi-square test or student t test was used.

\section{Results}

The mean Oc-C2 angle was smaller in male $\left(14.66+9.5^{\circ}\right)$ compared to $15.59+8.26^{\circ}$ in female individuals [Figure 2]; however, it was statistically insignificant $(P>0.05)$. The mean C1-C2 angle was smaller $\left(25.6+7.9^{\circ}\right)$ in male compared to 26.9 $+6.8^{\circ}$ in female $(\mathrm{Z}=4.13502, P<0.001)$ [Figure 3], which was

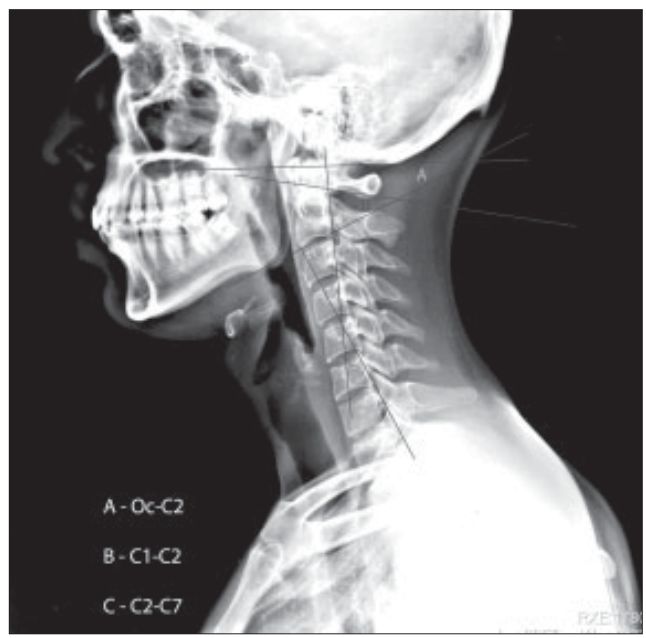

Figure 1: $X$-ray lateral cervical spine in neutral position showing various angles. Angle A (Oc-C2): Angle between McGregor line and the line tangential to the inferior aspect of the axis was defined as the Oc-C2 angle. Angle B (C1-C2): Angle between inferior aspect of atlas and axis. Angle C (C2-C7): Angle between the posterior aspect of vertebral bodies of $\mathrm{C} 2$ and $\mathrm{C} 7$.

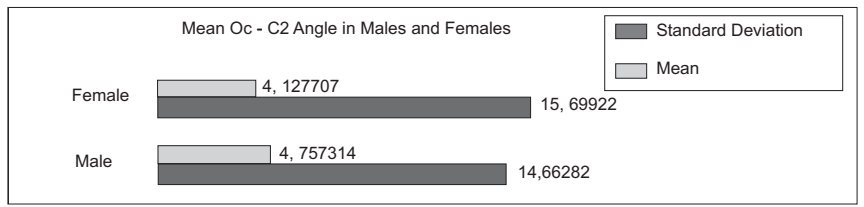

Figure 2: Age distribution in males and females (in years)

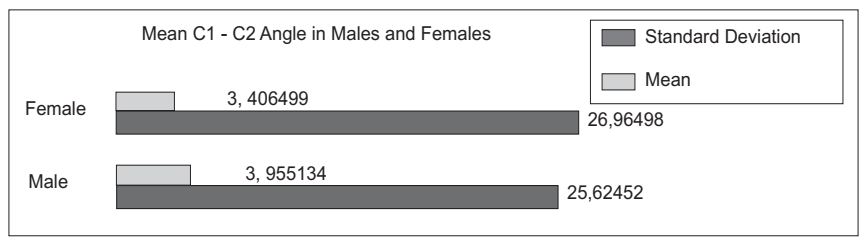

Figure 3: Mean Oc-C2 angle in males and females

\begin{tabular}{|ll|l|}
\hline \multirow{3}{*}{ Female } & Mean C2 - C7 Angle in Males and Females & \\
& & $\square$ Standard Deviation \\
$\square$ Mean
\end{tabular}

Figure 4: Mean C1-C2 angle in males and females statistically significant. The mean $\mathrm{C} 2-\mathrm{C} 7$ angle was larger in male $\left(16.8+12.7^{\circ}\right)$ compared to $9.11+10.4^{\circ}$ in female [Figure 4] $(\mathrm{Z}=15.2424, P<0.0001)$, which was also statistically significant.

The Oc-C2 angle correlated significantly with age in both male $(\mathrm{r}=-0.50762 ; \mathrm{t}=9.48 ; P<0.001$ at $259 \mathrm{df})$ and female individuals $(\mathrm{r}=-0.6255 ; \mathrm{t}=12.75 ; P<0.001$ at $255 \mathrm{df})$ up to the third decade of life. A statistically significant difference was observed between male and female individuals older than 60 years of age $(P<0.0001)$ and individuals in the fifth decade of life $(P<0.01)$. Age related changes in the $\mathrm{C} 1-\mathrm{C} 2$ angle were very small and there was no statistically significant correlation between this angle and age in either males $(\mathrm{r}=-0.18259 ; \mathrm{t}=2.99 ; P>0.05$ at $259 \mathrm{df})$ or females $(\mathrm{r}=-0.53869 ; \mathrm{t}=10.17 ; P>0.05$ at 255 df). The C2-C7 angle correlated significantly with age in both males $(\mathrm{r}=0.686356 ; \mathrm{t}=15.18 ; P<0.001$ at $259 \mathrm{df})$ and in females $(\mathrm{r}=0.607352 ; \mathrm{t}=12.160 ; P<0.001$ at $255 \mathrm{df})$ from 30 years onwards, i.e., the angle increases with age in both males and females; however, increase in males is significantly larger than in females in their fourth to sixth decades of life $(P<0.0001)$ and $(P<0.001)$ [Figure 5].

The correlation coefficient between the $\mathrm{Oc}-\mathrm{C} 2$ and $\mathrm{C} 2-\mathrm{C} 7$ angles was $(\mathrm{r}=-0.1244 ; \mathrm{t}=2.02 ; P<0.05$ at $259 \mathrm{df})$ in males and $(\mathrm{r}=$ $-0.49919 ; \mathrm{t}=9.16 ; P<0.001$ at $255 \mathrm{df})$ in females. The correlation coefficient between the C1-C2 and C2-C7 angles was $(\mathrm{r}=0.161164 ; \mathrm{t}=2.628044 ; P<0.05$ at $259 \mathrm{df})$ in males and $(\mathrm{r}=-0.4128 ; \mathrm{t}=7.21 ; P<0.001$ at $255 \mathrm{df})$ in females. Although weak statistically significant negative correlation was observed between the measured angles of the upper and lower cervical spines, which means if the lordosis of the occiput and upper cervical spine increases (the Oc-C2 angle increases), the alignment of lower cervical spine becomes kyphotic and vice versa. This negative

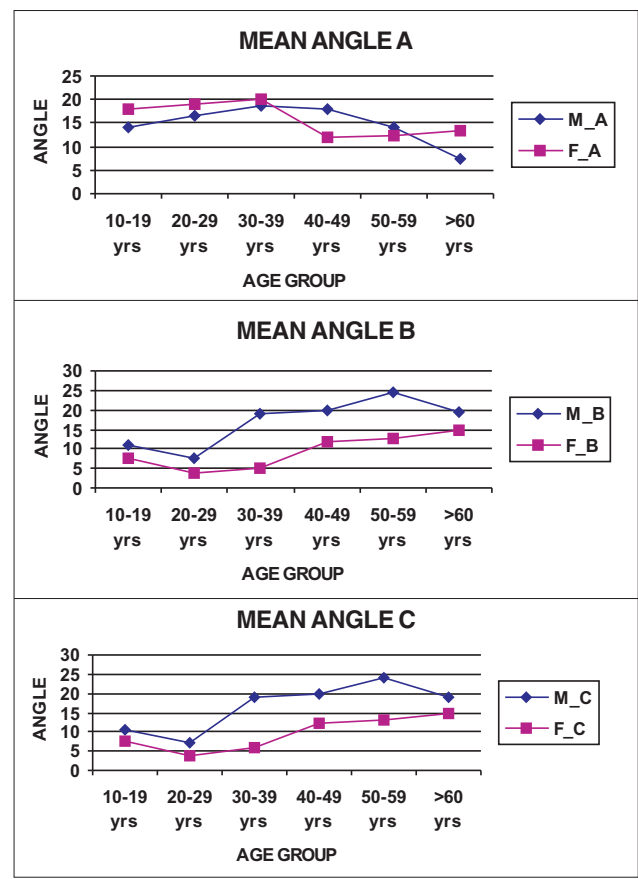

Figure 5: Mean C2-C7 angle in males and females 
correlation was stronger between the Oc-C2 and C2-C7 angles than between the $\mathrm{C} 1-\mathrm{C} 2$ and $\mathrm{C} 2-\mathrm{C} 7$ angles.

\section{Discussion}

Occipito-cervical alignment has been evaluated using different methods by different investigators and has been inconsistent, although there is no such study for the Indian population. The present study was conducted using a large number of asymptomatic individuals with uniform age distribution. In the present study, we had taken 518 asymptomatic volunteers (261 males and 257 females) between 12 and 80 years of age. They had no history of cervical disease or trauma and exhibited no neck, shoulder or arm symptoms.

The mean age was $39.47 \pm 17.08$ and $38.96 \pm 16.66$ years in males and females respectively. In the present study, the number of cases was uniformly distributed in each age group and both sexes so as to avoid age and sex bias; for instance, 41 males and 41 females were taken in 10-19 years of age group.

In our study, mean Oc-C2 angle was found to be $14.66+9.5^{\circ}$ in males and $15.59+8.26^{\circ}$ in females compared to $14.5+8^{\circ}$ in males and $16+8.5^{\circ}$ in females in Kenya Nojiri et $a l^{[10]}$ series. In our study, mean C1-C2 was found to be $25.6+7.9^{\circ}$ in males and $26.9+6.8^{\circ}$ in females [Figure 3], while it was $26.5+7^{\circ}$ in males and $28.9+6.7^{\circ}$ in females in Kenya Nojiri et $a l^{[10]}$ series. The mean $\mathrm{C} 2-\mathrm{C} 7$ angle was found to be $16.8+12.7^{\circ}$ and $9.11+$ $10.4^{\circ}$, respectively in males and females in our study [Figure 4], while it was $16.2+12.8^{\circ}$ in males and $10.5+10.3^{\circ}$ in females in Kenya Nojiri et $a l^{[10]}$ series.

In the present study, correlation was observed between Oc-C2 and $\mathrm{C} 2-\mathrm{C} 7$ angles $(\mathrm{r}=-0.1244$ in males and -0.49919 in females $)$ and between C1-C2 and C2-C7 ( $\mathrm{r}=0.161164$ in males and 0.4128 in females), which was also observed by Kenya Nojiri et $a l^{[10]}$ between Oc-C2 and C2-C7 angles $(r=-0.31$ in males and 0.37 in females) and between C1-C2 and C2-C7 ( $\mathrm{r}=0.22$ in males and -0.22 in females). We found that the mean C1-C2 was significantly larger in female individuals, whereas the mean C2$\mathrm{C} 7$ angle was significantly larger in male individuals. It was also found that the mean Oc-C2 had a weak negative correlation with C2-C7 angle, i.e., the alignment of the occiput and upper cervical spine and occiput and lower cervical spine are interrelated. If lordosis of the occiput and upper cervical spine increases (the Oc$\mathrm{C} 2$ angle increases), the alignment of lower cervical spine becomes kyphotic and vice versa. The small variation found in our results as compared to the study by Kenya Nojiri et al may be because of the difference in human races involved, different habitus, geographical and genetic factors.

There have been few studies regarding alignment values of the upper cervical spine, but there have been limitations in these studies as various authors have used different lines and were also subjective to position and cooperation of individuals. Phillips et $a l^{[11]}$ measured the occipito-cervical angle formed by Macrae line ${ }^{[12]}$ and superior aspect of $\mathrm{C} 3$ in 30 individuals in flexion, neutral and extension positions and found that the mean occipito-cervical angles were $24.2^{\circ}, 44^{\circ}$ and $57.2^{\circ}$ respectively. ${ }^{[1]]}$ The difference in the results between Phillips et al study and our series was because of different lines. The occipito-cervical "neutral" position is considered to be the most functional position of the cranium on the cervical vertebrae. Radiology texts define occipito-cervical neutral position as that position in which the subject looks straight ahead during a standard lateral cervical radiograph. In this position, mandible should not overlap C2 or C3. These criteria are obviously subjective and depend on conscious cooperation of the individual. ${ }^{[13-15]}$ Matsunaga et $a l^{[15]}$ measured the Oc-C2 angle between the McGregor's line and the inferior aspect of axis in 240 asymptomatic individuals and showed that the Oc-C2 angles were significantly greater in females than in males in all age groups; additionally, they reported that these angles gradually decreased with age after 40 years in both sexes. They found that the individuals who underwent occipito-cervical fusion within the mean normal value $+2 \mathrm{SD}$ for healthy volunteers of the relevant sex and age did not develop kyphosis or swan neck deformity compared to those who developed deformity, were fused in abnormal range. ${ }^{[15]}$ These findings indicate that in occipito-cervical fusion, the position of the fixation of the occipital bone and the axis should be within the range of $0-30^{\circ}$, taking into consideration long-term effects on the middle and lower cervical vertebrae.

In the present study, every possible effort was taken to reduce the error, but still there are chances of non-sampling errors, which need further confirmatory studies. This study gives only normal values in different age groups and both sexes in normal population of Indian origin. These values should be validated in further human studies.

\section{Conclusion}

In the present study, the normal ranges of values of the cervical spine for Indian population were established. It is found that the mean C1-C2 angle was significantly larger in female individuals. The mean C2-C7 angle was significantly larger in male individuals. The mean Oc-C2 angle had a weak negative correlation with the C2-C7 angle. The values presented in this study for the particular age and sex should be referred to when attempting occipito-cervical or other cervical fusions in appropriate alignment.

\section{References}

1. Mori T, Matsunaga S, Sunahara N, Sakou T. 3-to 11 years follow up of occipitocervical fusion for rheumatoid arthritis. Clin Orthop Relat Res 1998;351:169-79.

2. Matsumoto M, Fujimura Y, Suzuki N, Toyama Y, Shiga H. Cervical curvature in acute whiplash injuries: Prospective comparative study with asymptomatic subjects. Injury 1998;29:775-8.

3. Agarwal AK. Peppelman WC, Kraus DR, Pollock BH, Stolzer BL, Eisenbeis CH Jr, et al. Recurrence of cervical spine instability in rheumatoid arthritis following previous fusion; Can disease progression be prevented by early surgery? J Rheumatol 1992;19:1364-70.

4. Kraus DR, Peppelman WC, Agarwal AK. DeLeeuw HW, Donaldson WF $3^{\text {rdi }}$, Incidence of subaxial subluxation in individuals with generalized rheumatoid arthritis who have had previous occipital cervical fusions. Spine 1991;16:S486-9.

5. Krieg JC, Clark CR, Goetz DD. Cervical spine arthrodesis in rheumatoid arthritis: 
A long term follow-up, Yale J Biol Med 1993;66:257-62.

6. Toyama Y, Matsumoto M. Chiba K, Asazuma T, Suzuki N, Fujimura Y, et al. Realignment of post-operative cervical kyphosis in children by vertebral remodeling. Spine 1994;19:2565-70.

7. Jereny WR Young. Skeletal trauma: regional; In: David Sutton (editor) Text book of radiology and Imaging. $7^{\text {th }}$ ed. Churchill Livingstone: London; 2003. p. 1389-416.

8. Dull S, Toselli RM. Postoperative spinal deformation. In: Edward C. Benzel (editor): Spine surgery. Churchill Livingstone: Philadelphia; 1999. p. 1419-34.

9. McGregor M. The significance of certain measurements of the skull in the diagnosis of basilar impression. Br J Radiol 1948;21:171-81.

10. Nojiri K, Matsumoto M, Chiba K, Maruiwa H, Nakamura M, Nishizawa T, et al. Relationship between alignment of upper and lower cervical spine in asymptomatic individuals. J Neurosurg 2003;99:80-3.
11. Phillips FM, Phillips CS, Wetzel T, Gelinas C. Occipitocervical neutral position. Possible surgical implications. Spine 1999;24:775-8

12. Macrae IF, Wright V. Measurement of back movement. Ann Rheum Dis $1969 ; 28: 584-9$.

13. Ishihara A. Roentgenographic studies on the normal pattern of the cervical curvature. Nippon Seikeigeka Gakkai Zasshi 1968;42:1033-44.

14. Juhl JH, Miller SM, Roberts GW. Roetgenographic variations in the normal cervical spine. Radiology 1962;78:591-7.

15. Matsunaga S, Onishi T, Sakou T. Significance of occipitoaxial angle in sub axial lesion after occipitocervical fusion. Spine 2001;26:161-5.

Accepted on 20-07-2006

\section{Author Help: Choosing an appropriate category of article for faster publication}

The manuscript system (www.journalonweb.com) allows the authors to check a likely publication date for a newly submitted article. Based on number of articles in review, number of accepted articles and acceptance rate, the system estimates the likely publication date for an article submitted on a given date.

If there are too many articles in a category e.g., case report, a newly submitted case report if accepted may have to wait for a long period before publication. Hence, the author can check other categories e.g. letter to editor or images, for such paper and submit to another category of articles. 